Atmos. Chem. Phys., 18, 16499-16513, 2018

https://doi.org/10.5194/acp-18-16499-2018

(C) Author(s) 2018. This work is distributed under

the Creative Commons Attribution 4.0 License.

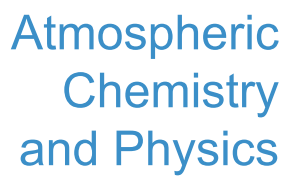

(c) (P)

\title{
Response of Arctic ozone to sudden stratospheric warmings
}

\author{
Alvaro de la Cámara ${ }^{1,2}$, Marta Abalos ${ }^{1}$, Peter Hitchcock ${ }^{3, a}$, Natalia Calvo ${ }^{1}$, and Rolando R. Garcia ${ }^{4}$ \\ ${ }^{1}$ Dept. Física de la Tierra y Astrofísica, Universidad Complutense de Madrid (UCM), Madrid, Spain \\ ${ }^{2}$ Instituto de Geociencias (IGEO), CSIC-UCM, Madrid, Spain \\ ${ }^{3}$ Laboratoire de Météorologie Dynamique/IPSL, Ecole Polytechnique, Palaiseau, France \\ ${ }^{4}$ National Center for Atmospheric Research, Boulder, CO, USA \\ ${ }^{a}$ now at: Earth and Atmospheric Sciences Dept., Cornell University, Ithaca, NY, USA
}

Correspondence: Alvaro de la Cámara (acamarai@ucm.es)

Received: 31 July 2018 - Discussion started: 21 August 2018

Revised: 23 October 2018 - Accepted: 5 November 2018 - Published: 21 November 2018

\begin{abstract}
Sudden stratospheric warmings (SSWs) are the main source of intra-seasonal and interannual variability in the extratropical stratosphere. The profound alterations to the stratospheric circulation that accompany such events produce rapid changes in the atmospheric composition. The goal of this study is to deepen our understanding of the dynamics that control changes of Arctic ozone during the life cycle of SSWs, providing a quantitative analysis of advective transport and mixing. We use output from four ensemble members (60 years each) of the Whole Atmospheric Community Climate Model version 4 performed for the Chemistry Climate Model Initiative and also use reanalysis and satellite data for validation purposes. The composite evolution of ozone displays positive mixing ratio anomalies of up to $0.5-$ $0.6 \mathrm{ppmv}$ above $550 \mathrm{~K}(\sim 50 \mathrm{hPa})$ around the central warming date and negative anomalies below ( -0.2 to $-0.3 \mathrm{ppmv})$, consistently in observations, reanalysis, and the model. Our analysis shows a clear temporal offset between ozone eddy transport and diffusive ozone fluxes. The initial changes in ozone are mainly driven by isentropic eddy fluxes linked to enhanced wave drag responsible for the SSW. The recovery of climatological values in the aftermath of SSWs is slower in the lower than in the upper stratosphere and is driven by the competing effects of cross-isentropic motions (which work towards the recovery) and isentropic irreversible mixing (which delays the recovery). These features are enhanced in strength and duration during sufficiently deep SSWs, particularly those followed by polar-night jet oscillation (PJO) events. It is found that SSW-induced ozone concentration anomalies below $600 \mathrm{~K}(\sim 40 \mathrm{hPa})$, as well as total column
\end{abstract}

estimates, persist around 1 month longer in PJO than in nonPJO warmings.

\section{Introduction}

Understanding the impact of dynamical processes such as sudden stratospheric warmings (SSWs) (e.g., Butler et al., 2015) on Arctic ozone is key to interpreting the observed interannual variability and better quantifying polar ozone evolution (WMO, 2014). The stratospheric circulation distributes ozone far from its photochemical production region in the tropics (e.g., Solomon et al., 1986; Hauchecorne et al., 2002). The global distribution of ozone is largely controlled by a balance between advection by the stratospheric overturning circulation, rapid isentropic stirring and mixing that follows planetary Rossby wave breaking, and chemical sources and sinks (e.g., Hartmann and Garcia, 1979; Garcia and Solomon, 1983; Plumb, 2002). A recent example of this seasonal balance was provided by Lubis et al. (2017), showing that reflective or absorptive wave conditions in the winter stratosphere result in lower or higher seasonal concentrations of Arctic ozone through adjustments in transport and chemical reaction rates. The extreme and transient nature of the dynamical forcing that triggers SSWs alters this balance. Driven by an abrupt growth of wave activity (e.g., Matsuno, 1971; McIntyre, 1982; Birner and Albers, 2017; de la Cámara et al., 2017), SSWs produce global changes in the middle atmospheric circulation that affect polar temperatures - and thus ozone depletion (Newman et al., 2001) and impact tracer transport and mixing (Randel et al., 2002). 
In a recent study, de la Cámara et al. (2018) used reanalysis data and model output from the Whole Atmosphere Community Climate Model (WACCM) to provide a composite view of the changes in transport and mixing properties of the flow during the life cycle of SSWs. They found that after the onset of SSWs, the residual circulation remains weak as a result of suppressed wave driving, but enhanced mixing nonetheless persists in the lower stratosphere for over 2 months. This study also showed a clear temporal offset between wave forcing and mixing; zonal-mean eddy fluxes of potential vorticity (PV) decay shortly after the SSW onset, while diffusive PV fluxes (in equivalent latitudes) remain active several weeks after. The de la Cámara et al. (2018) study found these anomalies in transport and mixing to be stronger and more persistent for those warming events that occur during a polar-night jet oscillation (PJO) event (Kodera et al., 2000; Hitchcock et al., 2013a). Note that the notion of PJO events in the present paper is similar to that in Hitchcock et al. (2013a) and de la Cámara et al. (2018) in the sense that PJO events are associated explicitly with SSWs (i.e., sufficiently deep SSWs). This differs from the perspective of Kodera et al. (2000), who saw the PJO as a low-frequency stratospheric mode of variability that sometimes phase locks with SSWs.

Case studies for several Arctic winters based on the combined use of observations and Lagrangian transport models highlight the wide range of inter-event variability and the sensitivity of polar chemical processing to the different dynamical conditions. Manney et al. (2003) used a Lagrangian transport model and ozone data from the Aura Microwave Limb Sounder (MLS) to estimate chemical ozone depletion in the polar vortex for the 1991/92 through 1997/98 boreal winters. They found large interannual variability in the timing and spatial patterns of ozone depletion due to variability in the position of the vortex and dynamical processes. Konopka et al. (2007) combined satellite observations of ozone from POAM (Polar Ozone and Aerosol Measurement III) and MIPAS (Michelson Interferometer for Passive Atmospheric Sounding) with simulations of the Chemical Lagrangian Model of the Stratosphere (CLaMS) to study the 2002/03 Arctic winter. They found that strong wave events associated with the 2003 SSW may have increased tracer transport and enhanced chemical ozone destruction in the polar vortex and its surroundings. The SSW in January 2009 was one of the strongest on record (e.g., Ayarzagüena et al., 2011; Albers and Birner, 2014). Both Manney et al. (2009) and Tao et al. (2015) highlight the enhanced isentropic mixing of trace gases across the vortex edge after the onset of the 2009 SSW, in agreement with the composite analysis of de la Cámara et al. (2018). Another example of the impact of a sudden warming on Arctic ozone is the 2015/2016 Northern Hemisphere winter, which was one of the coldest in the polar stratosphere in recent years. Intense ozone loss developed in February 2016 favored by the low Arctic temperatures, but was abruptly terminated by a sudden warming in early March that became one of the earliest final warmings on record (Khosrawi et al., 2017; Manney and Lawrence, 2016). Strahan et al. (2016) used reanalysis meteorological fields to integrate the Global Modeling Initiative (GMI) chemistry transport model for the 2005-2015 boreal winters and estimated that winters with SSWs before mid-February have about one-third the depletion of winters without SSWs. However, the cold, undisturbed vortex conditions of December 2012 , and the subsequent vortex split of early January that produced unusually long-lasting offspring vortices subject to high sunlight exposure, led to exceptionally high ozone depletion in January 2013 (Manney et al., 2015).

The present study aims to provide a quantitative evaluation of the changes in Arctic ozone induced during SSW events, using the Whole Atmosphere Community Climate Model (WACCM). The use of output from a free-running state-ofthe-art chemistry-climate model facilitates the evaluation of the separate contributions of transport-mixing and chemical processes to the ozone variations during the dynamically active boreal winter stratosphere, which is always a challenge for observational studies (Livesey et al., 2015). The 240 years of WACCM output will also provide the statistical robustness that the relatively short observational record lacks. We will show that the ozone field in WACCM shares many features with observations of the Microwave Limb Sounder (MLS) on the Aura satellite, and with reanalysis. The evaluation of the different terms of the zonal-mean ozone continuity equation in geometric latitude on isentropic levels, combined with the analysis of irreversible mixing diagnostics in equivalent latitude, will show that ozone anomalies during SSWs are mainly controlled by dynamical processes in the middle to lower stratosphere. In addition, sudden warmings that occur during a PJO event have stronger dynamically induced ozone anomalies that persist around 1 month longer than warmings without a PJO event.

The remainder of the paper is organized as follows. Section 2 describes the model runs, the observational data, and reanalysis used, and the diagnostics employed. Section 3 presents and discusses the results, and Sect. 4 gives the main conclusions.

\section{Data and methods}

\subsection{Model output and data}

WACCM is a global chemistry-climate model developed at the National Center for Atmospheric Research (NCAR) and can be used as the atmospheric module of the Community Earth System Model (CESM). The version used in this study, version 4 (Marsh et al., 2013), has a horizontal resolution of $2.5^{\circ} \times 1.9^{\circ}$ longitude-latitude and 66 levels in the vertical with the top at about $140 \mathrm{~km}$ in altitude. A few updates from Marsh et al. (2013) include a new chemistry module with revised heterogeneous chemistry (Wegner et al., 2013; 
Solomon et al., 2015) and changes to the orographic gravity wave parameterizations that significantly reduce the Antarctic cold pole bias (Garcia et al., 2017). We use daily averaged fields from four members of an ensemble of 60-year climate simulations (a total of 240 years; each ensemble member only differs in slightly different initial conditions of the atmospheric state) originally designed for the ChemistryClimate Model Initiative (CCMI) (Eyring et al., 2013; Morgenstern et al., 2017). These runs are forced with observed sea surface temperatures and external forcings for the period 1955-2014 (i.e., the CCMI REF-C1 configuration), and the quasi-biennial oscillation is nudged by relaxing the stratospheric tropical zonal winds towards observations (Marsh et al., 2013).

Two observational datasets and one reanalysis product are used for validation purposes. The ozone mixing ratio from the Stratospheric Water and Ozone Satellite Homogenized (SWOOSH) dataset for the period 1984-2017 (Davis et al., 2016) is used for a seasonal cycle comparison with the model. This monthly-mean merged ozone product combines observations from a set of satellite instruments (SAGE-II/III, UARS HALOE, and UARS and Aura MLS) after a homogenization process to account for inter-satellite biases and to minimize artificial jumps in the record (see Davis et al., 2016, for more information). For comparisons of the evolution of Arctic ozone during SSWs, we use the daily averaged zonalmean ozone mixing ratio from Aura MLSv3, which covers the period September 2004-July 2012 on a $7.5^{\circ}$ latitude grid, and daily output of ozone mixing ratio from the European Interim Reanalysis (ERAI), produced by the European Center for Medium-Range Weather Forecasts (Dee et al., 2011), for the period $1979-2012$ on a $1^{\circ} \times 1^{\circ}$ longitude-latitude grid. Dragani (2011) determined that the observation minus analysis residuals of ozone in ERAI are typically within $\pm 5 \%$ in the region of the ozone mixing ratio maximum at $10 \mathrm{hPa}$ and above, but larger up to around $20 \%$ in the lower stratosphere.

\subsection{Diagnostics of ozone transport}

We will use daily-mean WACCM output to evaluate the continuity equation of zonal-mean ozone concentration on isentropic levels (e.g., Andrews et al., 1987):

$$
\begin{aligned}
\partial_{t} \overline{\mathrm{O}}_{3} & =\bar{S}^{*}-\underbrace{a^{-1} \bar{v}^{*} \partial_{\phi} \overline{\mathrm{O}}_{3}-\bar{Q}^{*} \partial_{\theta} \overline{\mathrm{O}}_{3}}_{\text {mean advection }} \\
& +\underbrace{{\overline{\sigma_{\theta}}}^{-1}\left[(a \cos \phi)^{-1} \partial_{\phi}\left(M_{\phi} \cos \phi\right)+\partial_{\theta} M_{\theta}\right]}_{\text {eddy transport }} \\
& -{\overline{\sigma_{\theta}}}^{-1} \partial_{t} \overline{\sigma_{\theta}^{\prime} \mathrm{O}_{3}^{\prime}},
\end{aligned}
$$

where $\mathrm{O}_{3}$ denotes the ozone mixing ratio, $S$ is the net ozone tendency due to chemistry (chemical production minus loss), $(v, Q)$ are the meridional and cross-isentropic velocities $(Q$ is the diabatic heating rate), $\sigma_{\theta} \equiv-g^{-1} \partial_{\theta} p$ is the isentropic density, $a$ is the Earth radius, $\phi$ is latitude, $\theta$ is potential temperature, and $t$ is time. The vector $\boldsymbol{M}=\left(0, M_{\phi}, M_{\theta}\right)=$ $\left(0,-\overline{\left(\sigma_{\theta} v\right)^{\prime} \mathrm{O}_{3}^{\prime}},-\overline{\left(\sigma_{\theta} Q\right)^{\prime} \mathrm{O}_{3}^{\prime}}\right)$ is the eddy flux term, whose divergence can be interpreted as an eddy transport term. Overbars denote the zonal mean, primes denote departures from it, and stars denote mass-weighted, zonally averaged variables $\left(\bar{X}^{*}={\overline{\sigma_{\theta}}}^{-1} \overline{\sigma_{\theta} X}\right)$. Note that the second and third terms in the right-hand side of Eq. (1) represent advection (isentropic and cross-isentropic, respectively) by the zonal-mean overturning circulation. Also, the last term is usually quite small and will not be shown, but it has been taken into account to compute the balances.

The eddy transport term is frequently used as an estimate of the two-way mixing effect of Rossby wave breaking on tracer concentrations to distinguish it from the mean advective transport by the residual circulation (e.g., Abalos et al., 2013). However, this eddy transport term, computed as the divergence of the eddy tracer flux, does not completely separate the irreversible two-way mixing and it can include a component of reversible transport (see de la Cámara et al., 2018). Furthermore, there can be eddy transport of chemical species that is irreversible in the absence of wave breaking. This can occur when the waves are dissipated thermally, or when the chemical lifetime of a species changes along the wave trajectory (i.e., chemical eddy transport; see Hartmann and Garcia, 1979; Garcia and Hartmann, 1980). To explore in more detail the role of irreversible mixing in ozone tendencies during SSWs, we evaluate the normalized equivalent length squared (hereafter simply equivalent length) for ozone (Haynes and Shuckburgh, 2000):

$\Lambda_{\mathrm{eq}}^{\mathrm{O}_{3}}\left(\phi_{\mathrm{e}}, t\right) \equiv a^{2}\langle| \nabla_{\theta}$ const $\left.\left.\mathrm{O}_{3}\right|^{2}\right\rangle\left(\partial_{\phi_{\mathrm{e}}} \mathrm{O}_{3, \mathrm{e}}\right)^{-2}$,

where $\langle x\rangle$ represents the area average between consecutive tracer contours, and $\mathrm{O}_{3, \mathrm{e}}$ is the ozone mixing ratio in equivalent latitude $\phi_{\mathrm{e}}(\mathrm{EqL})$ coordinates (Butchart and Remsberg, 1986; Allen and Nakamura, 2003). This coordinate system assigns the area $A$ enclosed by a given tracer contour to a circle of latitude (i.e., the equivalent latitude) that is the boundary of the polar cap with the same area, $A=2 \pi a^{2}\left(1-\sin \phi_{\mathrm{e}}\right)$. $\Lambda_{\text {eq }}$ is proportional to the effective diffusivity $\kappa_{\text {eff }}$ (Nakamura, 1996) $\left(\Lambda_{\text {eq }}=\kappa_{\text {eff }} / \kappa\right)$, with $\kappa$ being a constant diffusion parameter that depends on the model's spatial resolution and the hyperdiffusivity scheme employed. The equivalent length (or the effective diffusivity) quantifies the changes in microscale diffusion due to the irreversible elongation of tracer contours mainly caused by large-scale Rossby wave breaking and subsequent stirring. In EqL coordinates, the continuity equation for ozone will therefore be given by

$$
\begin{aligned}
\partial_{t} \mathrm{O}_{3, \mathrm{e}} & =-\left(a \cos \phi_{\mathrm{e}}\right)^{-1} \partial_{\phi_{\mathrm{e}}}\left(F_{\mathrm{d}}^{\mathrm{O}_{3}} \cos \phi_{\mathrm{e}}\right) \\
& +(\text { diabatic and chemical terms }),
\end{aligned}
$$

where $F_{\mathrm{d}}^{O_{3}}=-a^{-1} \kappa_{\mathrm{eff}} \partial_{\phi_{\mathrm{e}}} \mathrm{O}_{3, \mathrm{e}}$ is the horizontal diffusive flux of ozone in EqL. Estimating the explicit value of $F_{\mathrm{d}}^{\mathrm{O}_{3}}$ 
is challenging since the constant diffusion parameter $\kappa$ of the model, which enters in the definition of $\kappa_{\text {eff }}$, is unknown. However, we will employ the equivalent length $\Lambda_{\text {eq }}^{\mathrm{O}_{3}}$ instead of the effective diffusivity $\kappa_{\text {eff }}$ to compute $F_{\mathrm{d}}^{\mathrm{O}_{3}}$ as they basically contain the same information. This will not affect our results since we are interested in the anomalies of this diagnostic during SSWs (and not in its absolute value). Also, note that there is no horizontal (isentropic) advection term (either by the mean flow or by the eddies) in Eq. (3) since it is embedded in the tracer-based coordinate system. The only horizontal process involved in the evolution of ozone in EqL is the first term in the right-hand side, which represents the mixing-induced ozone tendency.

\subsection{Methodology}

Sudden stratospheric warmings are identified in ERAI and WACCM applying the widely used criterion of Charlton and Polvani (2007). The day when the zonal-mean zonal wind at $60^{\circ} \mathrm{N}$ and $10 \mathrm{hPa}$ turns negative is set as the central warming date, provided that it occurs between November and March (i.e., midwinter warmings), the separation from the previous central date is longer than 20 days, and the wind returns to positive values for at least 10 consecutive days before 30 April. In the 34-year period of ERAI we identify 23 SSWs $\left(0.68 \mathrm{yr}^{-1}\right)$, while in the 240 years of WACCM simulations we have 152 SSWs $\left(0.63 \mathrm{yr}^{-1}\right)$. In the MLS period (September 2004-July 2012), we have six events as identified with ERAI.

We classify SSWs depending on whether or not they occur during PJO events. These events are identified following the procedure of Hitchcock et al. (2013a). Briefly, the PJO classification is carried out in terms of the first two empirical orthogonal functions (EOFs) of daily-mean polar-cap-averaged $\left(70^{\circ}-90^{\circ} \mathrm{N}\right)$ temperatures over the middle-atmospheric column, which both present a vertical dipole structure (Kodera et al., 2000). A PJO event is identified when the temperature anomaly (as projected onto these two EOFs) maximizes at a height of approximately $60 \mathrm{hPa}$, so long as it is sufficiently strong (see Hitchcock et al., 2013a, for further details). Consequently, SSWs that occur during PJO events will have a strong signal in the lower stratosphere, but note that the identification criterion does not explicitly consider the persistence of the anomalies. We find that $70 \mathrm{SSWs}$ occur during PJO events (hereafter PJO SSW) in WACCM, while 82 are not linked to PJO events (hereafter nPJO SSW).

The methodology followed consists of constructing composites of the fields as a function of latitude or altitude, centered on the SSW central date. The daily anomalies are calculated as the difference between the daily value and the daily climatological average (smoothed with a 10-day running mean). The statistical significance is assessed applying a two-tailed Student's $t$ test to compare the composite mean of SSWs and the climatology. We use $N-1$ degrees of freedom, $N$ being the number of SSWs included in the composite, and a confidence level of $99 \%$ (i.e., $\alpha=0.01$ ). Each SSW event has been assumed to be independent to estimate the degrees of freedom.

\section{Results}

\subsection{Annual cycle of ozone in observations, reanalysis, and WACCM}

We first compare the Northern Hemisphere seasonal cycle of ozone in SWOOSH (1980-2017), ERAI (1979-2012), and WACCM (240 years). Figure 1 shows the seasonal evolution of zonal-mean ozone mixing ratio at 10,70 , and $100 \mathrm{hPa}$ (or the nearest levels available) for the three data sources. As expected, in all datasets the latitudinal gradients have opposite signs in the lower and middle stratosphere (e.g., Brasseur and Solomon, 2005): ozone mixing ratio over the Arctic is smaller than in midlatitudes at $10 \mathrm{hPa}$, and the opposite is true at 70 and $100 \mathrm{hPa}$. Also, at 70 and $100 \mathrm{hPa}$ the seasonal cycle is characterized by maximum values in winter and minimum values in summer (consistent with the overturning circulation seasonality), while at $10 \mathrm{hPa}$ the minimum values occur in autumn over the polar cap. WACCM and ERAI present very similar values at the three levels shown, and there is good agreement with SWOOSH at $10 \mathrm{hPa}$. In the lower stratosphere (70 and $100 \mathrm{hPa}$ ) WACCM and ERAI agree well with observations, although both the model and reanalysis present mixing ratios around $10 \%$ larger than SWOOSH in winter over the Arctic, which matches the findings of Dragani (2011).

Figure 2 shows the contribution of each term in Eq. (1) to the simulated seasonal cycle of the ozone budget in WACCM, averaged over $70-90^{\circ} \mathrm{N}$ on the isentropic levels of $850 \mathrm{~K}(\sim 10 \mathrm{hPa}), 500 \mathrm{~K}(\sim 60 \mathrm{hPa})$, and $400 \mathrm{~K}(\sim 100 \mathrm{hPa})$. Note the transient eddy term (last term in Eq. 1) is usually very small and not shown here. At $850 \mathrm{~K}$ isentropic eddy transport and net chemical loss nearly balance each other, particularly from February to May, and vertical advection makes a small contribution in autumn and winter. As a result, the tendency is a small residual relative to these two competing effects. The polar middle stratosphere constitutes the transition layer above which ozone is chemically controlled and below which it is dynamically controlled (e.g., Brasseur and Solomon, 2005). This is evident in Fig. 2b, c, where the ozone budget terms are displayed at $500 \mathrm{~K}$ and $400 \mathrm{~K}$. At $500 \mathrm{~K}$, chemical destruction is still relevant in spring and summer, but the shape of the ozone seasonal cycle is mainly determined by the seasonally varying cross-isentropic advection and isentropic eddy transport (although the chemical sink in late spring and early summer delays the ozone minimum to midsummer). Downward motion in winter increases ozone over the pole, while isentropic eddy transport works against it, smoothing out the ozone meridional gradients. At $400 \mathrm{~K}$, the chemical term is practically irrelevant, 
(a) $\mathrm{O}_{3} 10 \mathrm{hPa}$ SWOOSH

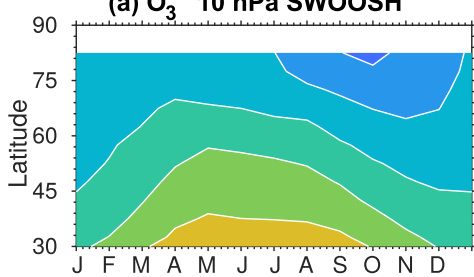

(d) $\mathrm{O}_{3} \quad 68.1 \mathrm{hPa}$ SWOOSH

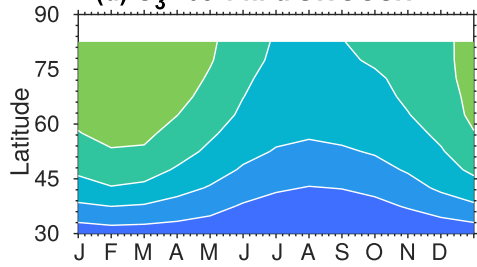

(g) $\mathrm{O}_{3} 100 \mathrm{hPa} \mathrm{SWOOSH}$

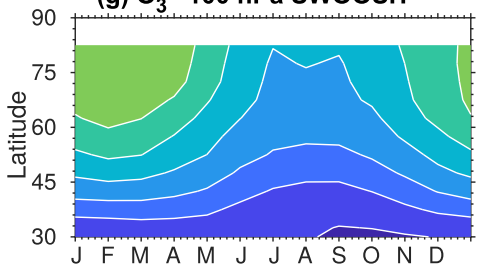

(b) $\mathrm{O}_{3} 9.9 \mathrm{hPa}$ ERAI

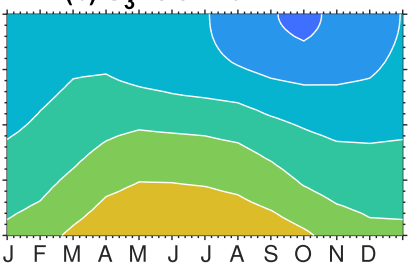

(e) $\mathrm{O}_{3} \quad 66.6 \mathrm{hPa}$ ERAI

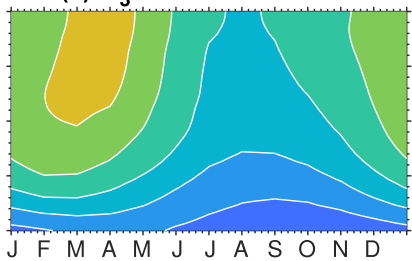

(h) $\mathrm{O}_{3} 96 \mathrm{hPa}$ ERAI

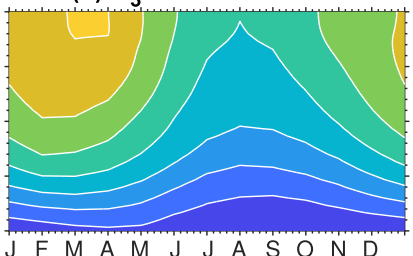

(c) $\mathrm{O}_{3} \quad 10.7 \mathrm{hPa}$ WACCM

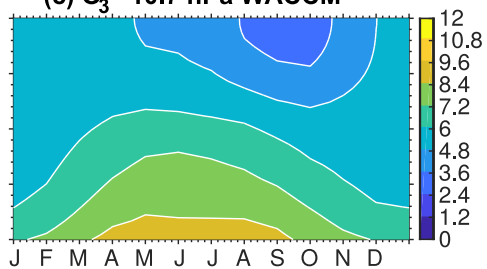

(f) $\mathrm{O}_{3} 72.9 \mathrm{hPa}$ WACCM

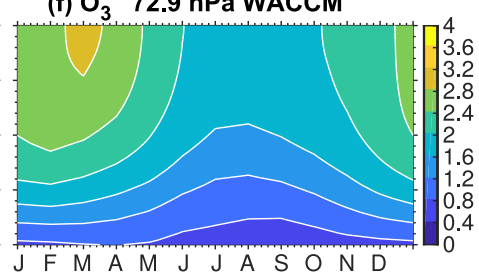

(i) $\mathrm{O}_{3} \quad 100.5 \mathrm{hPa}$ WACCM

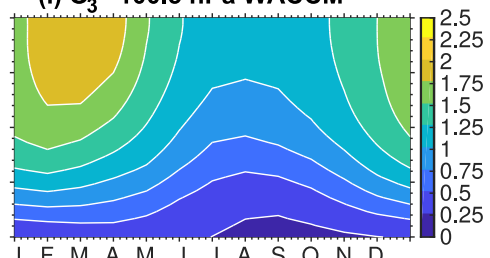

Figure 1. Climatological seasonal cycle of zonal-mean ozone (ppmv) north of $30^{\circ} \mathrm{N}$ at different pressure surfaces in the lower and midstratosphere for $(\mathbf{a}, \mathbf{d}, \mathbf{g})$ SWOOSH data, $(\mathbf{b}, \mathbf{e}, \mathbf{h})$ ERA-Interim, and $(\mathbf{c}, \mathbf{f}, \mathbf{i})$ WACCM output.
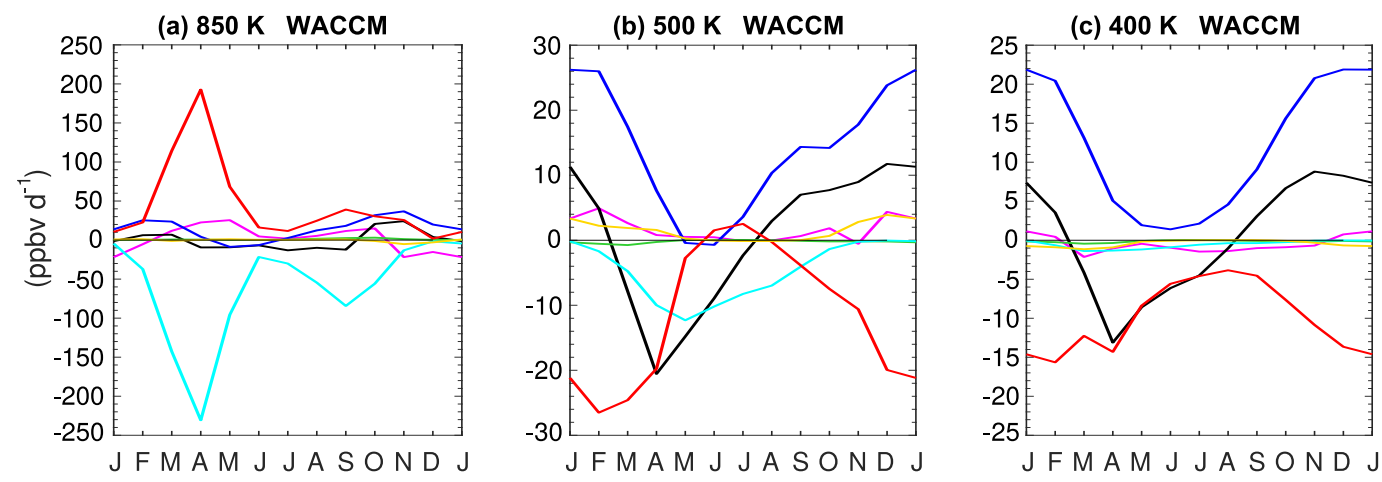

$-\partial_{\mathrm{t}} \mathrm{O}_{3}:$ ozone tendency $--\mathrm{a}^{-1} \mathrm{v}^{*} \partial_{\phi} \mathrm{O}_{3}:$ isentropic mean advection $-(\operatorname{a~cos} \phi)^{-1} \partial_{\phi}\left(\mathrm{M}_{\phi} \cos \phi\right)$ : isentropic eddy transport
- Residual $--\mathrm{Q}^{*} \partial_{\theta} \mathrm{O}_{3}:$ cross-isentropic mean advection $-\partial_{\theta} \mathrm{M}_{\theta}:$ cross-isentropic eddy transport $-\mathrm{S}^{*}:$ chemical tendency

Figure 2. Climatological seasonal cycle of the different terms in the ozone continuity equation (Eq. 1) averaged over the Arctic (70-90 $\mathrm{N}$ ) at (a) $850 \mathrm{~K}$, (b) $500 \mathrm{~K}$, and (c) $400 \mathrm{~K}$. WACCM output.

and the seasonal budget of ozone is completely controlled by the competing effects of cross-isentropic advection and isentropic eddy transport. The good agreement in the ozone seasonal cycle between WACCM and observations, as well as the reproduction of well-known features in the ozone budget, allows us to explore the driving mechanisms of ozone changes during the lifetime of SSWs using WACCM in the next subsections.

\subsection{Changes in polar ozone during SSWs}

Figure 3a, b, c show the composite anomalies of ozone in MLS, ERAI, and WACCM, respectively, averaged over the Arctic $\left(70-90^{\circ} \mathrm{N}\right)$ as a function of time lag with respect to the SSW central date (Fig. 3d will be discussed later). The three panels show very similar behavior despite the variety of datasets and years covered (note that the MLS composite is based on only six events). The Arctic ozone mixing ratio is enhanced $(0.5-0.6 \mathrm{ppmv})$ at levels at which ozone decreases poleward $(>550 \mathrm{~K})$ and reduced $(0.2-0.3 \mathrm{ppmv})$ at 

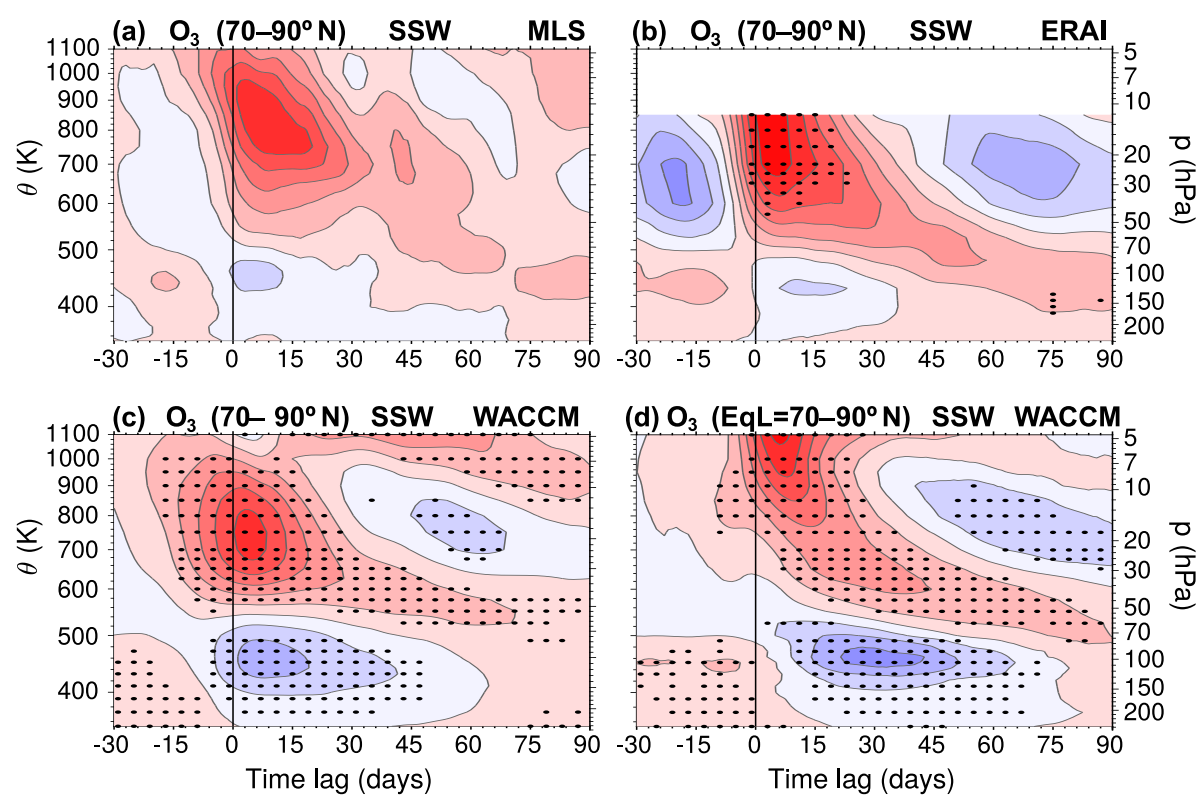

$\begin{array}{lllllllllllllllllllll}-1 & -0.9 & -0.8 & -0.7 & -0.6 & -0.5 & -0.4 & -0.3 & -0.2 & -0.1 & 0 & 0.1 & 0.2 & 0.3 & 0.4 & 0.5 & 0.6 & 0.7 & 0.8 & 0.9 & 1\end{array}$

Figure 3. Composite evolution around the SSW central day as a function of potential temperature of ozone concentration anomalies (ppmv) averaged over $70-90^{\circ} \mathrm{N}$ for (a) MLS, (b) ERAI, and (c) WACCM; (d) similar composite but averaging over EqL 70-90 $\mathrm{N}$ in WACCM. Black dots denote statistically significant anomalies (two-tailed Student's $t$ test, $\alpha=0.01$ ). Note that the statistical test has not been performed for MLS due to the small sample of SSWs. The approximate pressure level is indicated on the right axis.

levels at which it increases poleward $(<550 \mathrm{~K})$. MLS and ERAI show a sharper growth of the anomalies from lags -5 to 0 days (Fig. 3a, b), while in WACCM the growth is more gradual over the course of the 10 days preceding the central date (Fig. 3c). At positive lags there is a slow "descent" of positive ozone anomalies in the mid-stratosphere, and ozone returns to pre-warming values faster in the upper than in the lower stratosphere.

We can now take full advantage of WACCM meteorological fields and investigate the driving mechanisms of these anomalies during SSWs by evaluating the different terms in the zonal-mean ozone budget equation (Eq. 1). Figure 4 shows the anomalies of the most relevant terms of Eq. (1), including the ozone tendency (Fig. 4a), the isentropic and cross-isentropic mean advection (Fig. 4c, d, respectively), the isentropic eddy transport (Fig. 4e), and the chemical production minus loss (Fig. 4f). The cross-isentropic eddy transport and eddy transient terms (the last two terms in Eq. 1) are very small and will not be shown. Note that instead of showing the residual, Fig. $4 \mathrm{~b}$ displays the ozone tendency $\left(\left.\partial_{t} \overline{\mathrm{O}}_{3}\right|_{i}\right)$ that results from the sum of all the terms in the right-hand side of Eq. (1), and it can be compared with the direct calculation of the ozone tendency in Fig. 4a. There is a relatively good agreement between the direct and "indirect" calculations of the ozone tendency below $\sim 700-800 \mathrm{~K}$ (Fig. 4a, b). However, some discrepancies appear at $\theta>800 \mathrm{~K}$, which are likely due to uncertainties in the calculation of the eddy transport term (note that periods of large discrepancy between $\partial_{t} \overline{\mathrm{O}}_{3}$ and $\left.\partial_{t} \overline{\mathrm{O}}_{3}\right|_{i}$ at $\theta>800 \mathrm{~K}$, such as at lags $45-60$ and 75 days, coincide with periods of very large anomalies of isentropic eddy transport at those levels in Fig. 4e). This in turn can be due to differences in the numerical formulations between the model transport scheme and our offline diagnostics. Another source of discrepancy is that in Eq. (1) we do not include the effects of numerical diffusion, and vertical diffusion due to the gravity wave parameterization in WACCM, which are presumably non-negligible in the middle to upper stratosphere.

Over the 2 weeks prior to the central date (lags $-15-$ 0 days), the isentropic eddy transport leads off the ozone changes (Fig. 4e). This indicates that the initial increase in ozone mixing ratio at negative lags above and decrease below $\sim 550 \mathrm{~K}$ (Figs. $3 \mathrm{c}$ and $4 \mathrm{a}$ ) is primarily a consequence of the growth of planetary waves in the stratosphere that ultimately triggers the SSW. Other terms of Eq. (1) make a relatively smaller albeit significant contribution at this early stage, such as a growing cross-isentropic advection that increases ozone below $900 \mathrm{~K}$ and decreases ozone above $900 \mathrm{~K}$ (Fig. 4d), negative anomalies of isentropic mean advection at levels higher than $500 \mathrm{~K}$, and large negative chemical tendencies above $700 \mathrm{~K}$ (Fig. 4f) that tend to restore photochemical equilibrium in response to the dynamically induced ozone anomalies. In the aftermath of the warming (positive lags), the anomalies of cross-isentropic advection present a downward-progressing structure (Fig. 4d) that leads to a gradual return to climatological values of ozone be- 

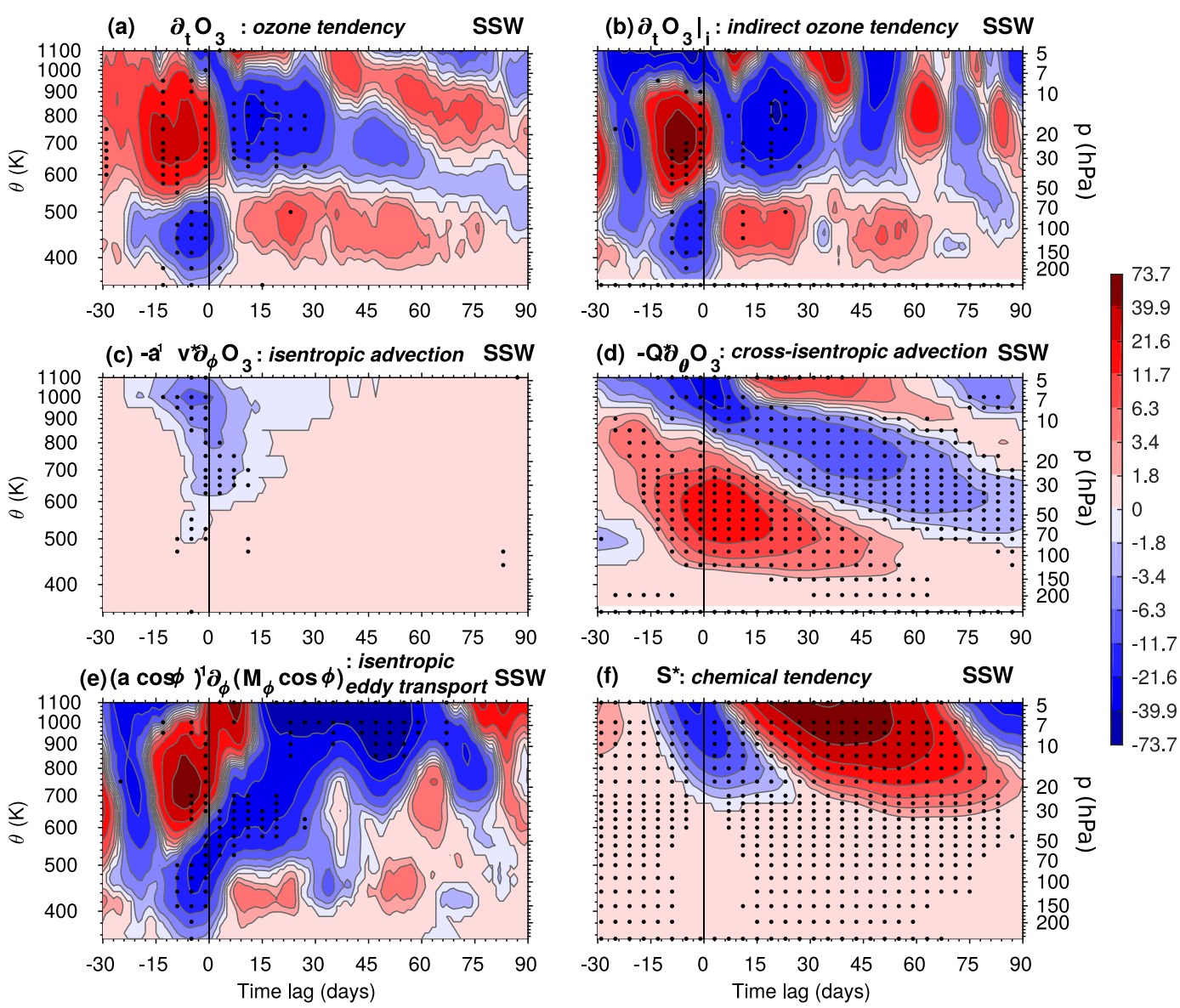

Figure 4. Composite evolution, centered on the SSW central date, of the anomalies of the different terms in the zonal-mean ozone continuity equation (Eq. 1) ( $\mathrm{ppbv} \mathrm{d}^{-1}$ ) as a function of potential temperature, averaged over $70-90^{\circ} \mathrm{N}$, for WACCM. Black dots indicate statistically significant values (two-tailed Student's $t$ test, $\alpha=0.01$ ).

low $500 \mathrm{~K}$. Above $500 \mathrm{~K}$ in the middle and upper stratosphere, where wave activity is suppressed in the aftermath of the warming (e.g., Limpasuvan et al., 2004; Hitchcock and Shepherd, 2013; de la Cámara et al., 2017), reduced isentropic eddy transport and cross-isentropic advection allow the ozone mixing ratio (Fig. 3c) to recover at a much faster rate (Fig. 4e), while chemical tendencies partially counteract these effects.

Extracting the effects of irreversible mixing from the Eulerian-mean eddy transport term is a challenging task, and no effort will be made to do so here. Instead, we use the equation for the evolution of ozone in the equivalent latitude EqL framework (Eq. 3), in which the only isentropic process that modifies ozone is irreversible mixing (see Sect. 2.2). Figure $3 \mathrm{~d}$ shows the evolution of ozone anomalies averaged over EqL $\phi_{\mathrm{e}}=70-90^{\circ} \mathrm{N}$. The structure of ozone anomalies in $\mathrm{EqL}$ is overall similar to that in geographical coordinates (Fig. 3c), but there are details that provide a somewhat different perspective. The level of maximum positive anomalies in EqL appears to be located at altitudes higher than $1100 \mathrm{~K}$ (while in geographical coordinates it is located at
$700-800 \mathrm{~K})$. But the most significant difference is that the initial changes in ozone appear around 1 week later in EqL than those over the geographical polar cap at all levels (compare Fig. 3c, d). It should be noted that the average over $\phi_{\mathrm{e}}=70-90^{\circ} \mathrm{N}$ in EqL encompasses the interior of the polar vortex, especially at negative lags. Therefore, the initial ozone increase over the Arctic (in geographical coordinates) above $600 \mathrm{~K}$ that starts at a lag of -15 days (Fig. 3c) does not happen inside the vortex; otherwise it would have been captured in EqL coordinates. Additionally, we conclude now that those changes should be a consequence of reversible isentropic eddy transport in Fig. 4e (as opposed to irreversible mixing) since ozone in EqL (which can only be changed by nonconservative processes; see Eq. 3) does not present those changes.

To explore this feature in more detail, the left column of Fig. 5 shows the evolution of the anomalies of ozone tendency in EqL (Fig. 5a) and mixing-induced ozone tendency (first term in the right-hand side of Eq. 3) (Fig. 5d) averaged over the EqL $\phi_{\mathrm{e}}=70-90^{\circ} \mathrm{N}$ during SSWs. Note that the central and right panels in Fig. 5 will be discussed in Sect. 3.3. 

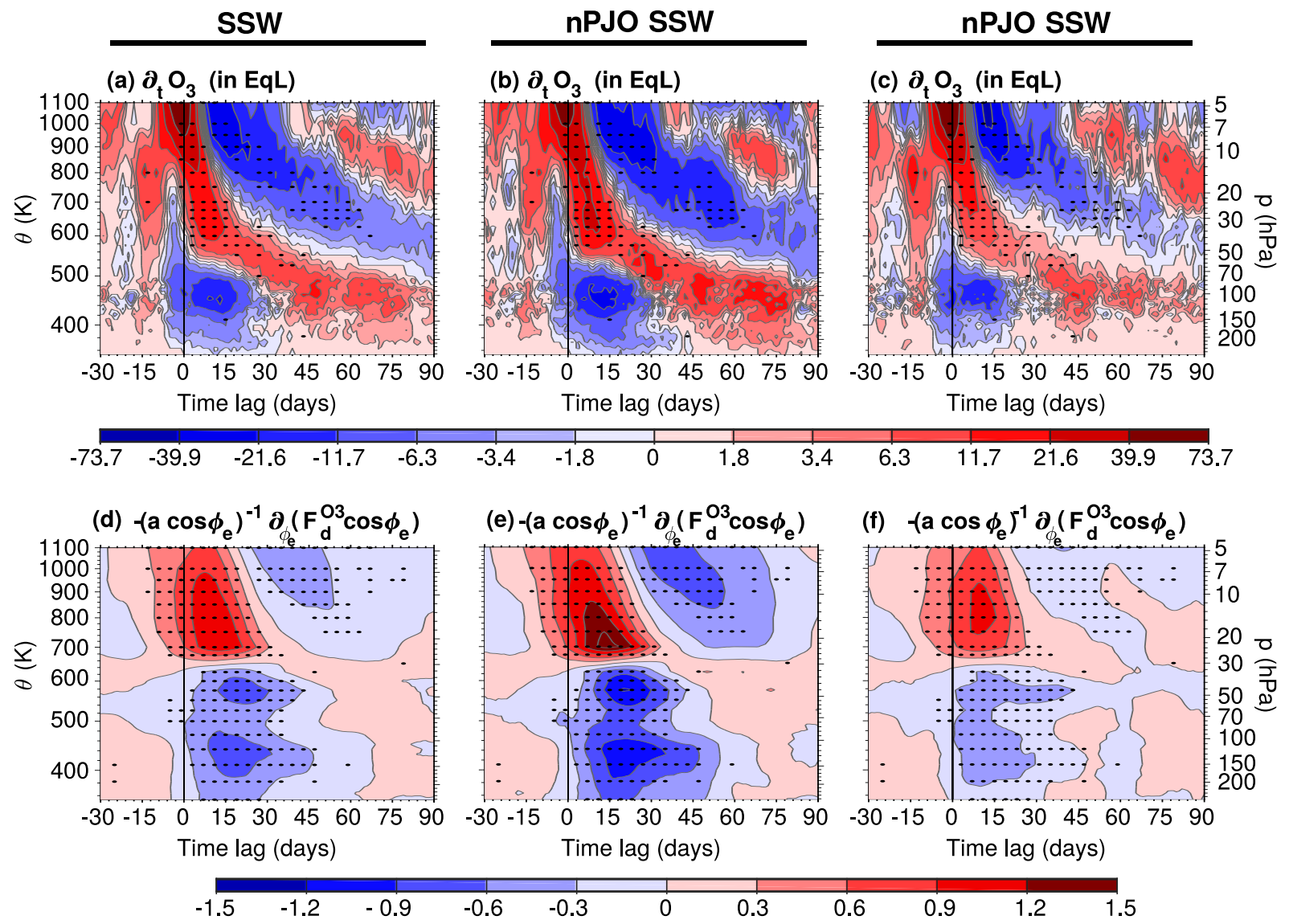

Figure 5. Composite evolution, centered on the SSW central date and averaged over equivalent latitudes $\phi_{\mathrm{e}}=70-90^{\circ} \mathrm{N}$, of (a, b, c) anomalies of ozone tendencies ( $\mathrm{ppbv} \mathrm{d}^{-1}$ ), and $(\mathbf{a}, \mathbf{b}, \mathbf{c})$ the standardized anomalies of mixing-induced ozone tendencies (see Eq. 3). (a, d) All SSW events in WACCM, (b, e) PJO SSW events, and (c, f) nPJO SSW events. Black dots indicate statistically significant values (two-tailed Student's $t$ test, $\alpha=0.01)$.

The anomalies of the mixing-induced tendency term have been normalized by the standard deviation at each isentrope since we cannot compute the absolute value of the diffusive flux of ozone $F_{\mathrm{d}}^{\mathrm{O}_{3}}$ (see Sect. 2.2). A comparison between Fig. 5a and d reveals that the initial changes in ozone in EqL share timing with enhanced irreversible mixing, which tends to reduce ozone below $\sim 600 \mathrm{~K}$ and increase ozone above $\sim 600 \mathrm{~K}$ (Fig. $5 \mathrm{~d}$ ). The ozone-induced mixing anomalies persist well after the onset of SSWs, up to a lag of 30 days in the middle and upper stratosphere and up to a lag of 45 days in the lower stratosphere.

Consistent with what was mentioned at the end of the previous paragraph, there is practically no sign of enhanced mixing at negative lags, confirming the reversible nature of the Eulerian-mean isentropic eddy transport increase at negative lags in Fig. 4e. The timing and duration of the mixinginduced ozone tendencies are dominated by the behavior of the anomalies of the equivalent length $\Lambda_{\mathrm{eq}}^{\mathrm{O}_{3}}$, which are shown in the left column of Fig. 6 at the $850 \mathrm{~K}, 450 \mathrm{~K}$, and $400 \mathrm{~K}$ isentropes (the central and right panels in Fig. 6 will be discussed in Sect. 3.3). The anomalies of $\Lambda_{\mathrm{eq}}^{\mathrm{O}_{3}}$ during SSWs have a similar latitudinal structure and evolution to $\Lambda_{\mathrm{eq}}$ computed from the PV field at these levels (de la Cámara et al., 2018), which emphasizes that the evolution of ozone is dominated by the dynamics. Positive anomalies of $\Lambda_{\mathrm{eq}}^{\mathrm{O}_{3}}$ (enhanced mixing properties) start at $850 \mathrm{~K}$ and a lag of -10 days in the midlatitudes, migrating poleward at positive lags lasting until a lag of 30 days, and being replaced by a period of weak mixing. As we move down to lower altitudes the positive anomalies of $\Lambda_{\mathrm{eq}}^{\mathrm{O}_{3}}$ appear increasingly delayed and persist for longer than 2 months at $450-400 \mathrm{~K}$.

The study of de la Cámara et al. (2018) showed that the response of irreversible mixing to wave breaking during SSWs is not instantaneous, but extends over several weeks (as long as 2 months in the lower stratosphere) after the large-scale wave forcing has decayed. This behavior is reproduced in the comparison of the zonal-mean isentropic eddy transport of ozone $\left((a \cos \phi)^{-1} \partial_{\phi}\left(M_{\phi} \cos \phi\right)\right)$ and the mixing-induced ozone tendency in $\operatorname{EqL}\left(-\left(a \cos \phi_{\mathrm{e}}\right)^{-1} \partial_{\phi_{\mathrm{e}}}\left(F_{\mathrm{d}}^{\mathrm{O}_{3}} \cos \phi_{\mathrm{e}}\right)\right)$ in Figs. $4 \mathrm{e}$ and 5d, respectively. On the one hand, the Eulerianmean eddy transport term increases ozone above and de- 

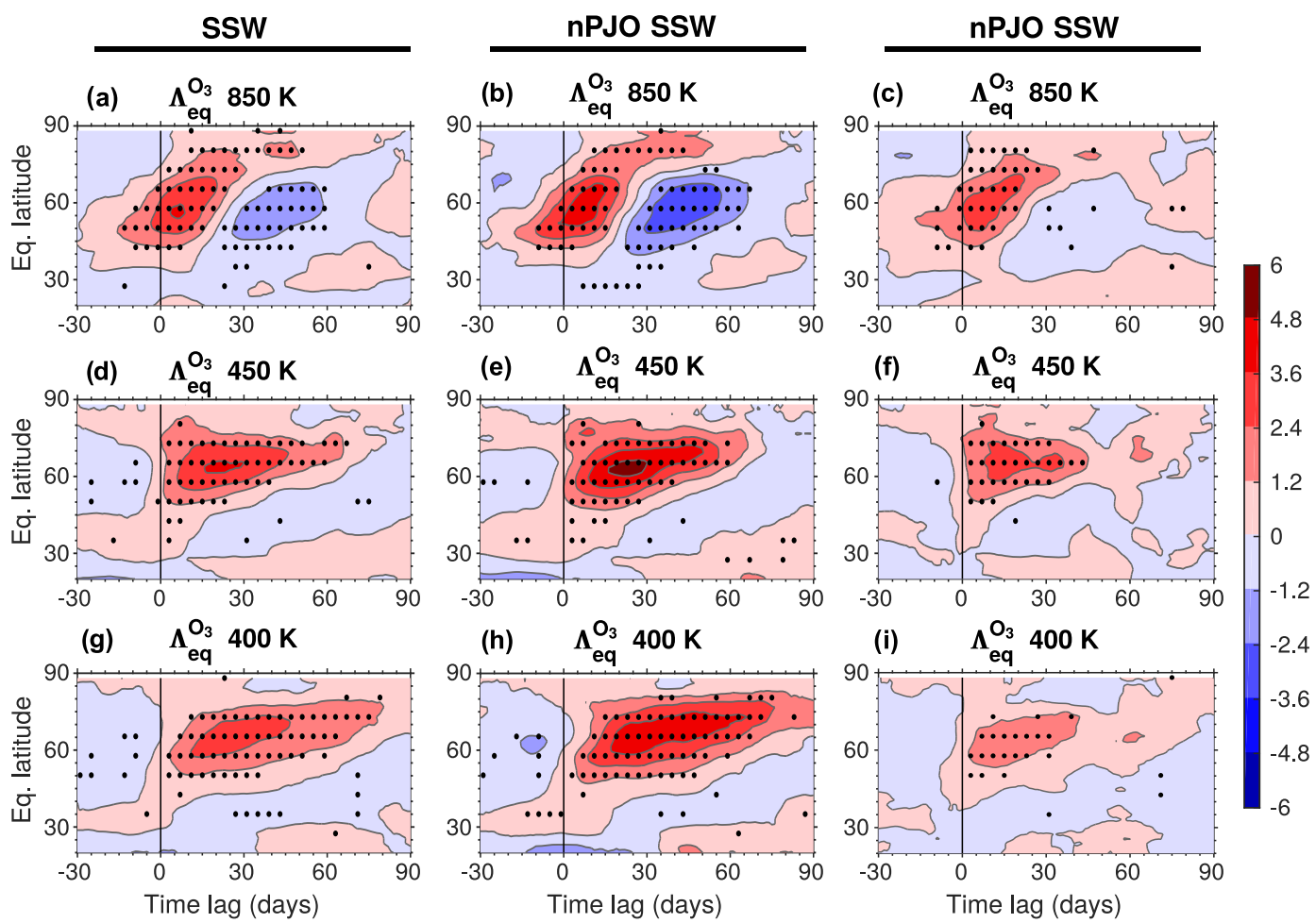

Figure 6. Composite evolution centered on the SSW central date as a function of EqL of equivalent length $\Lambda_{\mathrm{eq}}^{\mathrm{O}_{3}}$ anomalies (nondimensional units), for (a, d, g) all SSW events, (b, e, h) PJO SSW events, and (c, f, i) nPJO SSW events in WACCM, at $850 \mathrm{~K}, 500 \mathrm{~K}$, and $400 \mathrm{~K}$ as indicated. Black dots indicate statistically significant values (two-tailed Student's $t$ test, $\alpha=0.01$ ).

creases ozone below $\sim 600 \mathrm{~K}$ (i.e., smooths out the horizontal gradients) at negative lags, and then the anomalies reverse sign tightly following the behavior of the wave forcing during SSWs (e.g., Limpasuvan et al., 2004). On the other hand, the ozone gradient-smoothing effect of enhanced irreversible mixing persists long after the wave forcing (and the Eulerian-mean eddy transport) have declined. Part of this temporal offset may be explained as follows. The wave forcing (e.g., Eliassen-Palm flux divergence from a transformed Eulerian mean perspective or meridional eddy PV transport from an Eulerian perspective) distorts PV contours in geometric coordinates and fluxes PV (and ozone) across latitude circles (zonal-mean isentropic eddy transport). This is fast, occurs in the week or two prior to the central dates of the composite, and is reversible (e.g., if the wave packet propagates through and the contours return to zonal). At this point the air within the vortex in EqL has not changed so the lack of ozone anomalies in EqL prior to the central date is consistent (Fig. 3d). After the planetary waves break, the ozone (and PV) contours remain perturbed with smaller-scale motions, giving rise to slow irreversible mixing. Indeed, the role of nonconservative processes such as mixing in the aftermath of SSWs is to damp wave activity and delay the recovery of the vortex, particularly in the lower stratosphere (Lubis et al., 2018b, a; de la Cámara et al., 2018). Note that this discussion on reversible versus irreversible trans- port is based on WACCM results. However, the fact that ozone anomalies in ERAI and WACCM evolve similarly during SSWs (Fig. 3b, c), as well as the resemblance of ERAI and WACCM dynamics during SSWs (de la Cámara et al., 2018), makes us consider this discussion to be also relevant for ERAI.

\subsection{Modulation by PJO events}

Recent studies have shown that SSWs that occur during a PJO event (PJO SSW) experience larger alterations in circulation and temperature than those warmings that occur without a PJO event (nPJO SSW), particularly in the recovery phase (e.g., Hitchcock and Shepherd, 2013). Figure 7 shows that PJO and nPJO warmings also have different signatures in polar ozone. The vertical structure and evolution of the composite anomalies in $\mathrm{PJO}$ and $\mathrm{nPJO}$ events, both in polar cap and equivalent latitude averages (top and bottom panels, respectively, in Fig. 7), are similar to those for all the events (Fig. 3c, d). However, the magnitude of the anomalies is larger (below $500 \mathrm{~K}$ ozone anomalies are twice as large), and their persistence in the aftermath is much longer in PJO than in nPJO SSWs.

The evolution of the different terms in the zonal-mean balance equation (Eq. 1) averaged over the polar cap $\left(70-90^{\circ} \mathrm{N}\right)$ is shown in Fig. 8 at the $850 \mathrm{~K}$ and $450 \mathrm{~K}$ isentropes. We fo- 

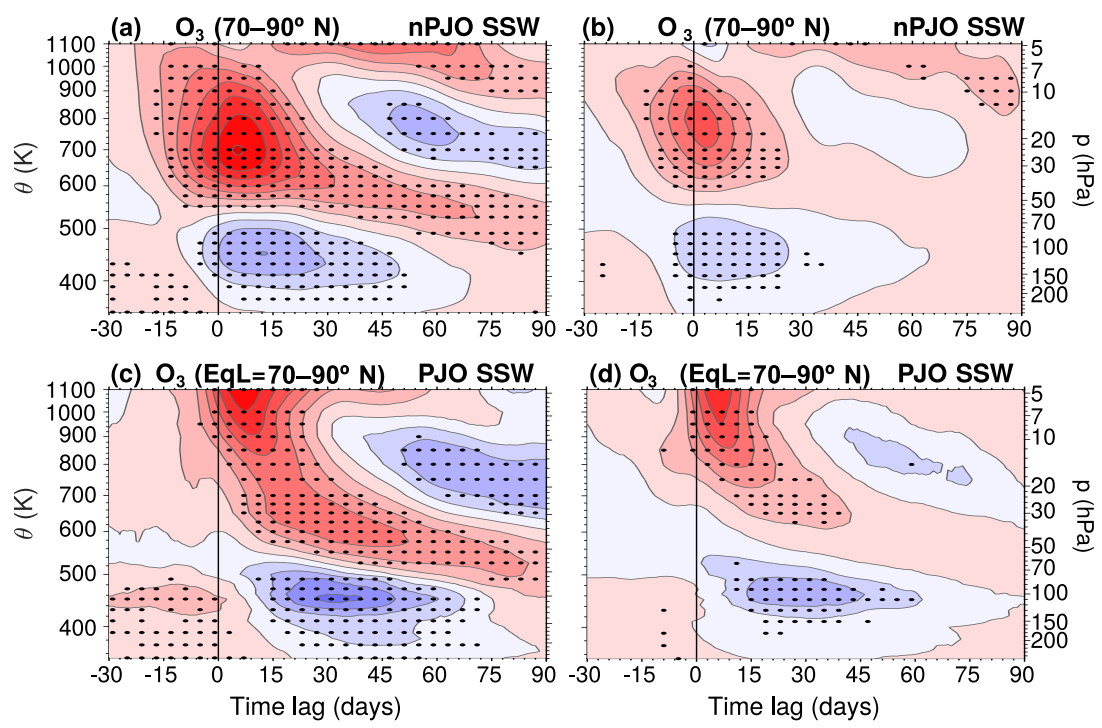

$\begin{array}{lllllllllllllllllllll}-1 & -0.9 & -0.8 & -0.7 & -0.6 & -0.5 & -0.4 & -0.3 & -0.2 & -0.1 & 0 & 0.1 & 0.2 & 0.3 & 0.4 & 0.5 & 0.6 & 0.7 & 0.8 & 0.9 & 1\end{array}$

Figure 7. As in Fig. 3, but for PJO SSW and nPJO SSW events in WACCM.

cus first on the days prior to the onset of the SSW, i.e., at negative lags. The tendencies of ozone in this period (black line), positive at $850 \mathrm{~K}$ and negative at $450 \mathrm{~K}$, are dominated by the isentropic eddy transport term (red line). At $850 \mathrm{~K}$ the anomalies of isentropic eddy transport are shorter lived but with higher peak values in nPJO than PJO events. At $450 \mathrm{~K}$, the eddy transport anomalies are quite similar in PJO and $\mathrm{nPJO}$ events, but the vertical advection (dark blue line) starts to build up more strongly around a lag of -10 days for PJO than for nPJO warmings. We focus next on the aftermath of the SSWs, in which the disparate evolution of ozone between PJO and nPJO events has several contributors depending on the vertical level. In the mid-stratosphere at $850 \mathrm{~K}$ (Fig. 8a, b), the isentropic eddy transport (red line) term becomes negative more abruptly in the first days after the central date in PJO than in nPJO events, transporting more ozone out of the polar cap. Also, the strong suppression of wave driving in the aftermath of PJO SSWs in the mid-stratosphere leads to a super-recovery of very cold polar temperatures (e.g., Hitchcock and Shepherd, 2013). The subsequent stronger positive anomalies of diabatic heating in PJO than in nPJO events (e.g., Hitchcock et al., 2013b; de la Cámara et al., 2018) produce larger negative vertical advection of ozone (dark blue line) in the former than in the latter that lasts until a lag of 60 days (Fig. 8a, b). These stronger dynamical tendencies result in larger negative ozone anomalies in the 700-900 K layer starting at a lag of 40 days in PJO than in nPJO warmings (compare Fig. 7a, b), which in turn induces stronger positive chemical tendencies (cyan line in Fig. 8a, b) trying to restore ozone to its photochemical equilibrium (Fig. 8a, b). In the lower stratosphere at $450 \mathrm{~K}$ (Fig. 8c, d), there are no significant differences between PJO and $\mathrm{nPJO}$ events in terms of intensity and timescale of the anomalies prior to a lag of 0 days. At positive lags, the eddy transport anomalies (red line) fluctuate around zero, and the main difference between PJO and nPJO events is the larger contribution (around 3 times as large) of vertical advection (dark blue line in Fig. 8c, d) to the recovery of ozone values in $\mathrm{PJO}$ than in $\mathrm{nPJO}$ events.

Figure 5e, $\mathrm{f}$ show the mixing-induced tendencies of ozone in EqL coordinates for PJO and nPJO SSWs. Consistent with the stronger ozone anomalies during the former than during the latter, the gradient-smoothing effect of mixing is stronger in PJO than in nPJO events. The central and right panels of Fig. 6 show that PJO SSWs produce larger and longer-lasting changes in equivalent length of ozone than nPJO events. Again, the differences between PJO and nPJO are more pronounced in the lower stratosphere: positive $\Lambda_{\text {eq }}^{\mathrm{O}_{3}}$ anomalies (i.e., enhanced ozone mixing properties) are 3 times as large and last over 30 days longer after PJO SSWs than after nPJO SSWs.

The impact of PJO and nPJO sudden warmings on ozone concentrations agrees well with what is expected from the differentiated responses in the advective overturning circulation and irreversible mixing identified in ERAI and WACCM by de la Cámara et al. (2018) for these two types of warmings. Particularly in the lower stratosphere, they found that the enhanced mixing and the anomalies of the vertical component of the overturning circulation were twice as strong, and lasted 1 month longer in PJO than in nPJO warmings. Hitchcock et al. (2013b) presented evidence indicating that this longer duration of the effects of PJO over nPJO warmings is due to the long radiative timescales in the lower stratosphere (e.g., Dickinson, 1973). PJO SSW events are charac- 
(a) $850 \mathrm{~K} \mathrm{nPJO} \mathrm{SSW}$

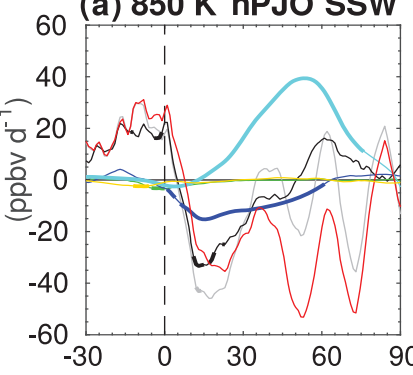

(c) $450 \mathrm{~K} \mathrm{nPJO} \mathrm{SSW}$

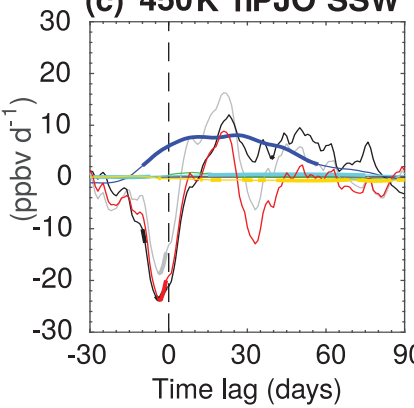

(b) $850 \mathrm{~K} \mathrm{nPJO} \mathrm{SSW}$

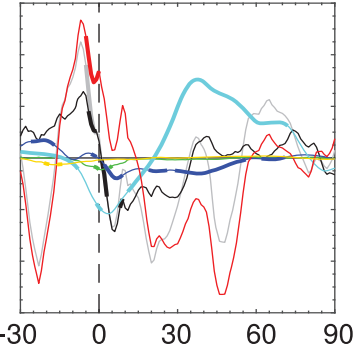

(d) $450 \mathrm{~K} \mathrm{nPJO} \mathrm{SSW}$

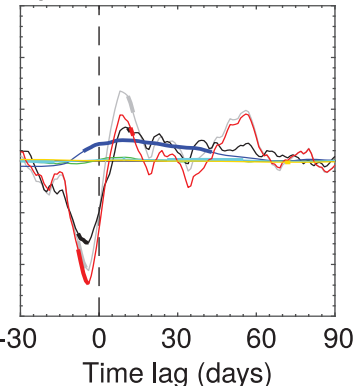

$\begin{array}{|cc|}-\partial_{\mathrm{t}} \mathrm{O}_{3}: \text { ozone tendency } & -\mathrm{a}^{-1} \mathrm{v}^{*} \partial_{\phi} \mathrm{O}_{3}: \text { isentropic mean } \\ \text { advection } \\ -\partial_{\mathrm{t}} \mathrm{O}_{3} \mathrm{l}_{\mathrm{i}}: \text { indirect ozone } & -\mathrm{Q}^{*} \partial_{\theta} \mathrm{O}_{3}: \text { cross-isentropic } \\ \text { mean advection } & \\ -(\mathrm{a} \cos \phi)^{-1} \partial_{\phi}\left(\mathrm{M}_{\phi} \cos \phi\right): \text { isentropic eddy transport } \\ -\partial_{\theta} \mathrm{M}_{\theta}: \text { cross-isentropic eddy transport } \begin{array}{c}\mathrm{S}^{*} \text { : chemical } \\ \text { tendency }\end{array} \\ \end{array}$

Figure 8. Composite evolution of the anomalies of the different terms in Eq. (1) at $850 \mathrm{~K}$ and $450 \mathrm{~K}$, averaged over $70-90^{\circ} \mathrm{N}$. (a, c) PJO SSW and (b, d) nPJO SSW. Thick lines indicate statistically significant values (two-tailed Student's $t$ test, $\alpha=0.01$ ). WACCM output.

terized by a deeper and stronger penetration of the warming into the lower stratosphere, where radiative relaxation timescales are very slow (Hitchcock et al., 2013b). Along with enhanced, long-lasting diffusive flux of PV (de la Cámara et al., 2018), they both work to ensure anomalous circulation and temperature conditions for longer times after the onset of the event, delaying the recovery of the vortex.

\subsection{Response in total ozone column}

Several studies have found that interannual variations in winter extratropical total ozone column (TOC) are well correlated with variations in planetary wave activity in the lower stratosphere (e.g., Kinnersley and Tung, 1998; Fusco and Salby, 1999; Randel et al., 2002). Planetary wave activity affects both the mean advection and mixing of ozone, so those correlations are a simple and useful way of isolating the contribution of dynamics to interannual variations in TOC. There were also early indications that SSWs are followed by large increases in polar TOC after SSWs (e.g., London, 1963).
To complement the analysis of composite changes of ozone based on ozone mixing ratios, we have calculated the resulting zonal-mean anomalies of TOC during SSWs using MLS, ERAI, and WACCM (Fig. 9, top row).

The three composites in the top row of Fig. 9 show a significant increase in TOC north of $45^{\circ} \mathrm{N}$ with a maximum larger than 25 DU (Dobson units) in MLS and 47 DU in ERAI and WACCM starting a few days before the SSW central date. A TOC reduction larger than 2 DU in MLS and 3.6 DU in ERAI and WACCM appears south of $45^{\circ} \mathrm{N}$; in MLS the reduction of TOC is confined to subtropical latitudes. The change of sign of TOC anomalies at $\sim 45^{\circ} \mathrm{N}$ is approximately coincident with the climatological position of the maximum latitudinal gradient in WACCM (not shown) and in observations (Garane et al., 2018). As happens with mixing ratio anomalies, the changes in TOC are present over 40-50 days (Fig. 9) after the SSW onset. In addition, the bottom row of Fig. 9 shows the corresponding TOC anomalies for PJO and nPJO SSWs in WACCM. TOC anomalies are stronger and last longer in the former than in the latter (peak values over the pole around twice as large, 47 versus $25 \mathrm{DU}$; note the logarithmic scale), indicating that PJO SSW events have more profound impacts in total column values through deeper alterations of the stratospheric circulation and associated transport and mixing (see Hitchcock et al., 2013a; de la Cámara et al., 2018, and Figs. 5 and 8). Fusco and Salby (1999) noted the fluctuating nature of TOC, locally sensitive to reversible transport. For instance, the number density increases as air descending along isentropic surfaces compresses, resulting in higher TOC, and this descent must be compensated for elsewhere by expansion of air along rising isentropic surfaces. However, reversible transport is unlikely behind the long-lasting, north-south dipole pattern in TOC during the life cycle of SSWs. Figures 4, 5, 6, and 8 all show that cross-isentropic advection and isentropic irreversible mixing are the main dynamical processes that change ozone mixing ratios during SSWs, in varying proportions at different heights and time lags, and which operate at longer timescales than the driving wave force.

\section{Summary and conclusions}

We have used 240 years of CESM/WACCM climate simulations, run with observed external forcings and boundary conditions for the period 1955-2014, to quantify variations in Arctic ozone during SSWs and their driving mechanisms. Composites of vertical profiles of polar cap (70$90^{\circ} \mathrm{N}$ ) anomalies of ozone concentrations on isentropic surfaces during the life cycle of SSWs show common features in MLS data, ERA-Interim, and WACCM (Fig. 3). Starting a few days before the SSW onset, there is a higher ozone mixing ratio at levels at which ozone decreases towards the pole (roughly above $550 \mathrm{~K}$ ) and a lower ozone mixing ratio where ozone increases towards the pole (below $\sim 550 \mathrm{~K}$ ). 
(a)TOC SSW MLS

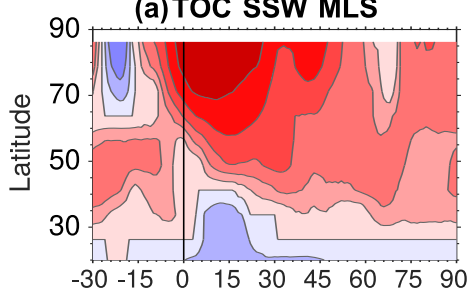

(b) TOC SSW ERAI

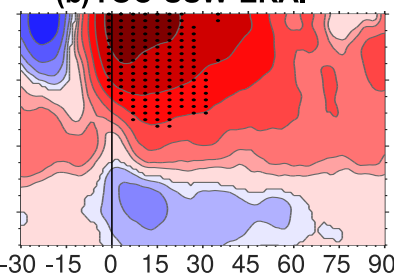

(c) TOC SSW WACCM

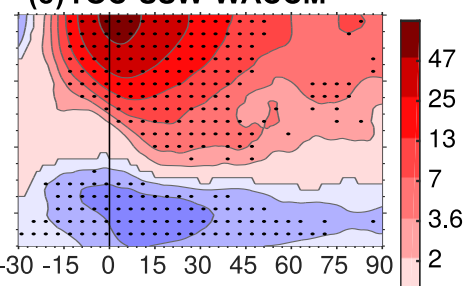

(e) TOC PJO SSW WACCM

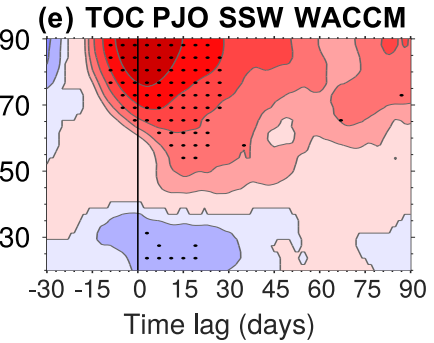

Time lag (days)

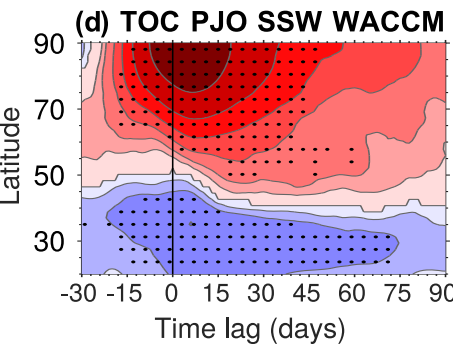

Figure 9. Composite evolution, centered on the SSW central date, of total ozone column (TOC) anomalies (DU) as a function of latitude. Composite for (a) SSWs in MLS, (b) SSWs in ERAI, (c) SSWs in WACCM, (d) PJO SSWs in WACCM, and (e) nPJO SSWs in WACCM. Black dots indicate statistically significant values (two-tailed Student's $t$ test, $\alpha=0.01$ ) (the statistical test has not been performed for MLS data due to the small sample of SSWs).

Enhanced isentropic eddy transport is the dominant driver of these anomalies during the onset period. From a zonally averaged perspective in geographical coordinates, the imbalance between suppressed eddy transport and reinforced cross-isentropic advection is responsible for the slow recovery of the ozone field in the aftermath of the warming that lasts over 1.5 months below $\sim 600 \mathrm{~K}$ (Fig. 4).

Based on WACCM diagnostics, we have found substantial differences in the timing when the ozone anomalies appear in geographical and equivalent latitude $(\mathrm{EqL})$ averages, which highlight the different dynamical processes involved. In geographical coordinates the initial polar ozone anomalies grow around 1 week earlier than in EqL, which indicates the reversible (conservative) nature in the initial changes of the zonal-mean isentropic eddy transport. Conversely, ozone anomalies in EqL averages $\left(\phi_{\mathrm{e}}=70-90^{\circ} \mathrm{N}\right)$ appear and disappear at the same time as anomalies in irreversible isentropic mixing of ozone, as diagnosed with the equivalent length $\Lambda_{\text {eq }}^{\mathrm{O}_{3}}$ (Eq. 2) and derived diffusive fluxes (Eq. 3). Particularly in the lower stratosphere, where radiative timescales are much longer than in the upper stratosphere, the gradientsmoothing effect of enhanced isentropic mixing of ozone persists over 2 months after the SSW onset (Figs. 5 and 6), contributing to the delay of the Arctic ozone recovery in the aftermath of SSWs. The clear temporal offset between enhanced eddy transport of ozone, which operates in the SSW onset, and enhanced irreversible mixing, which operates in the aftermath of the events, is in good agreement with recent estimates of eddy transport and mixing of PV during SSWs (de la Cámara et al., 2018).

The large sample of SSWs in the WACCM runs (152 in 240 years) allows a statistically robust evaluation of differ- ent types of SSW, namely those that are classified as PJO events and those that are not (PJO SSW and nPJO SSW, respectively). These two types of SSWs are characterized by different evolutions of polar temperature and zonal winds in the aftermath of the SSW (Hitchcock et al., 2013a) and different intensity and duration of the anomalous stratospheric transport and mixing properties (de la Cámara et al., 2018). We have found that polar ozone undergoes larger variations (anomalies up to $50 \%$ as large) that last longer in PJO than in $\mathrm{nPJO}$ events Fig. 7. While the evolution of isentropic eddy transport anomalies does not particularly differ between PJO and nPJO SSWs, irreversible isentropic mixing of ozone and mean cross-isentropic advection of ozone (nonconservative effects) are stronger and persist longer in the aftermath of PJO than in nPJO warmings. These are manifestations of larger and more persistent circulation anomalies in the former than in the latter (de la Cámara et al., 2018; Hitchcock and Shepherd, 2013).

The reported changes in ozone mixing ratios also affect total column values (Fig. 9). TOC estimates from MLS, ERAI, and WACCM present reasonable agreement, with high-latitude increases of $\sim 47$ DU peaking a few days after the SSW onset and subtropical decreases of around 3.6 DU (MLS column ozone has slightly weaker anomalies). The dipole structure of TOC anomalies lasts around 40-50 days after the SSW onset but is more persistent in PJO SSWs (around 2 months) than during nPJO SSWs (1 month).

The results of the present study contribute to a better interpretation of the observed interannual variability in Arctic ozone and a better quantification of its evolution, with particular emphasis on the effects of irreversible mixing. However, the impacts of SSWs on the ozone field reach tropical 
latitudes as suggested in Fig. 9. The exploration of tropical ozone variability during SSWs and its interaction with the quasi-biennial oscillation, will be explored in a future study.

Data availability. Data from ERA-Interim are freely available at http://apps.ecmwf.int/datasets/. The output from the WACCM runs is available at https://www2.acom.ucar.edu/gcm/ccmi-output and also upon request to the corresponding author. The SWOOSH dataset is available at https://www.esrl.noaa.gov/csd/groups/csd8/ swoosh/ (Davis et al., 2016).

Author contributions. AdlC, MA, and PH conceived and designed the study. AdlC performed the data analysis with input from all coauthors on the interpretation and discussion of results. AdlC led the paper writing with significant contributions from all co-authors.

Competing interests. The authors declare that they have no conflict of interest.

Acknowledgements. The authors are grateful to Mengchu Tao and the one anonymous referee for their positive assessment and constructive comments. This work has been partially funded by the Spanish national projects PALEOSTRAT (CGL2015-69699) and STEADY (CGL2017-83198-R) and the European project STRATOCLIM (FP7-ENV.2013.6.1-2 ref:603557). Alvaro de la Cámara has been supported by the UCM fellowship program "Personal posdoctoral en formación en investigación y docencia" and Marta Abalos by the research grant Atracción de Talento Comunidad de Madrid (ref 2016-T2/AMB-1405).

Edited by: Peter Haynes

Reviewed by: Mengchu Tao and one anonymous referee

\section{References}

Abalos, M., Ploeger, F., Konopka, P., Randel, W. J., and Serrano, E.: Ozone seasonality above the tropical tropopause: reconciling the Eulerian and Lagrangian perspectives of transport processes, Atmos. Chem. Phys., 13, 10787-10794, https://doi.org/10.5194/acp-13-10787-2013, 2013.

Albers, J. R. and Birner, T.: Vortex Preconditioning due to Planetary and Gravity Waves prior to Sudden Stratospheric Warmings, J. Atmos. Sci., 71, 4028-4054, https://doi.org/10.1175/JAS-D-140026.1, 2014.

Allen, D. R. and Nakamura, N.: Tracer Equivalent Latitude: A Diagnostic Tool for Isentropic Transport Studies, J. Atmos. Sci., 60, 287-304, https://doi.org/10.1175/15200469(2003)060<0287:TELADT>2.0.CO;2, 2003.

Andrews, D. G., Holton, J. R., and Leovy, C. B.: Middle atmosphere dynamics, Academic Press, San Diego, California, 1987.

Ayarzagüena, B., Langematz, U., and Serrano, E.: Tropospheric forcing of the stratosphere: A comparative study of the two different major stratospheric warm- ings in 2009 and 2010, J. Geophys. Res., 116, D18114, https://doi.org/10.1029/2010JD015023, 2011.

Birner, T. and Albers, J. R.: Sudden Stratospheric Warmings and Anomalous Upward Wave Activity Flux, SOLA, 13A, 8-12, https://doi.org/10.2151/sola.13A-002, 2017.

Brasseur, G. and Solomon, S.: Aeronomy of the middle atmosphere: Chemistry and physics of the stratosphere and mesosphere, Springer, 2005.

Butchart, N. and Remsberg, E. E.: The area of the stratospheric polar vortex as a diagnostic for tracer transport on an isentropic surface, J. Atmos. Sci., 43, 1319-1339, https://doi.org/10.1175/15200469(1986)043<1319:TAOTSP>2.0.CO;2, 1986.

Butler, A. H., Seidel, D. J., Hardiman, S. C., Butchart, N., Birner, T., and Match, A.: Defining Sudden Stratospheric Warmings, Bull. Am. Meteorol. Soc., 96, 1913-1928, https://doi.org/10.1175/BAMS-D-13-00173.1, 2015.

Charlton, A. J. and Polvani, L. M.: A New Look at Stratospheric Sudden Warmings. Part I: Climatology and Modeling Benchmarks, J. Climate, 20, 449-469, https://doi.org/10.1175/JCLI3996.1, 2007.

Davis, S. M., Rosenlof, K. H., Hassler, B., Hurst, D. F., Read, W. G., Vömel, H., Selkirk, H., Fujiwara, M., and Damadeo, R.: The Stratospheric Water and Ozone Satellite Homogenized (SWOOSH) database: a long-term database for climate studies, Earth Syst. Sci. Data, 8, 461-490, https://doi.org/10.5194/essd8-461-2016, 2016.

de la Cámara, A., Albers, J. R. J., Birner, T., Garcia, R. R., Hitchcock, P., Kinnison, D. E. D., and Smith, A. A. K.: Sensitivity of sudden stratospheric warmings to previous stratospheric conditions, J. Atmos. Sci., 74, 2857-2877, https://doi.org/10.1175/JAS-D-17-0136.1, 2017.

de la Cámara, A., Abalos, M., and Hitchcock, P.: Changes in Stratospheric Transport and Mixing During Sudden Stratospheric Warmings, J. Geophys. Res.-Atmos., 123, 3356-3373, https://doi.org/10.1002/2017JD028007, 2018.

Dee, D. P., Uppala, S. M., Simmons, A. J., Berrisford, P., Poli, P., Kobayashi, S., Andrae, U., Balmaseda, M. A., Balsamo, G., Bauer, P., Bechtold, P., Beljaars, A. C. M., van de Berg, L., Bidlot, J., Bormann, N., Delsol, C., Dragani, R., Fuentes, M., Geer, A. J., Haimberger, L., Healy, S. B., Hersbach, H., Hólm, E. V., Isaksen, L., Kållberg, P., Köhler, M., Matricardi, M., McNally, A. P., Monge-Sanz, B. M., Morcrette, J.-J., Park, B.-K., Peubey, C., de Rosnay, P., Tavolato, C., Thépaut, J.-N., and Vitart, F.: The ERA-Interim reanalysis: configuration and performance of the data assimilation system, Q. J. R. Meteorol. Soc., 137, 553-597, https://doi.org/10.1002/qj.828, 2011.

Dickinson, R. E.: Method of parameterization for infrared cooling between altitudes of 30 and 70 kilometers, J. Geophys. Res., 78, 4451-4457, https://doi.org/10.1029/JC078i021p04451, 1973.

Dragani, R.: On the quality of the ERA-Interim ozone reanalyses: comparisons with satellite data, Q. J. R. Meteorol. Soc., 137, 1312-1326, https://doi.org/10.1002/qj.821, 2011.

Eyring, V., Lamarque, J.-F., Hess, P., Arfeuille, F., Bowman, K., Chipperfield, M. P., Duncan, B., Fiore, A., Gettelman, A., Giorgetta, M. A., Granier, C., Hegglin, M., Kinnison, D., Kunze, M., Langematz, U., Luo, B., Martin, R., Matthes, K., Newman, P. A., Peter, T., Robock, A., Ryerson, T., Saiz-Lopez, A., Salawitch, R., Schultz, M., Shepherd, T. G., Shindell, D., Stähelin, J., Tegt- 
meier, S., Thomason, L., Tilmes, S., Vernier, J.-P., Waugh, D. W., and Young, P. J.: Overview of IGAC/SPARC Chemistry-Climate Model Initiative (CCMI) Community Simulations in Support of Upcoming Ozone and Climate Assessments, SPARC Newsl., 40, 48-66, 2013.

Fusco, A. C. and Salby, M. L.: Interannual Variations of Total Ozone and Their Relationship to Variations of Planetary Wave Activity, J. Climate, $12, \quad 1619-1629$, https://doi.org/10.1175/15200442(1999)012<1619:IVOTOA>2.0.CO;2, 1999.

Garane, K., Lerot, C., Coldewey-Egbers, M., Verhoelst, T., Koukouli, M. E., Zyrichidou, I., Balis, D. S., Danckaert, T., Goutail, F., Granville, J., Hubert, D., Keppens, A., Lambert, J.-C., Loyola, D., Pommereau, J.-P., Van Roozendael, M., and Zehner, C.: Quality assessment of the Ozone_cci Climate Research Data Package (release 2017) - Part 1: Ground-based validation of total ozone column data products, Atmos. Meas. Tech., 11, 13851402, https://doi.org/10.5194/amt-11-1385-2018, 2018.

Garcia, R. R. and Hartmann, D. L.: The Role of Planetary Waves in the Maintenance of the Zonally Averaged Ozone Distribution of the Upper Stratosphere, J. Atmos. Sci., 37, 2248-2264, https://doi.org/10.1175/15200469(1980)037<2248:TROPWI>2.0.CO;2, 1980.

Garcia, R. R. and Solomon, S.: A numerical model of the zonally averaged dynamical and chemical structure of the middle atmosphere, J. Geophys. Res., 88, 1379, https://doi.org/10.1029/JC088iC02p01379, 1983.

Garcia, R. R., Smith, A. K., Kinnison, D. E., de la Cámara, Á., and Murphy, D. J.: Modification of the Gravity Wave Parameterization in the Whole Atmosphere Community Climate Model: Motivation and Results, J. Atmos. Sci., 74, 275-291, https://doi.org/10.1175/JAS-D-16-0104.1, 2017.

Hartmann, D. L. and Garcia, R. R.: A Mechanistic Model of Ozone Transport by Planetary Waves in the Stratosphere, J. Atmos. Sci., 36, 350-364, https://doi.org/10.1175/15200469(1979)036<0350:AMMOOT>2.0.CO;2, 1979.

Hauchecorne, A., Godin, S., Marchand, M., Heese, B., and Souprayen, C.: Quantification of the transport of chemical constituents from the polar vortex to midlatitudes in the lower stratosphere using the high-resolution advection model MIMOSA and effective diffusivity, J. Geophys. Res., 107, 8289, https://doi.org/10.1029/2001JD000491, 2002.

Haynes, P. and Shuckburgh, E.: Effective diffusivity as a diagnostic of atmospheric transport: 1. Stratosphere, J. Geophys. Res.-Atmos., 105, 22777-22794, https://doi.org/10.1029/2000JD900093, 2000.

Hitchcock, P. and Shepherd, T. G.: Zonal-Mean Dynamics of Extended Recoveries from Stratospheric Sudden Warmings, J. Atmos. Sci., 70, 688-707, https://doi.org/10.1175/JAS-D-120111.1, 2013.

Hitchcock, P., Shepherd, T. G., and Manney, G. L.: Statistical Characterization of Arctic Polar-Night Jet Oscillation Events, J. Climate, 26, 2096-2116, https://doi.org/10.1175/JCLI-D-1200202.1, 2013a.

Hitchcock, P., Shepherd, T. G., Taguchi, M., Yoden, S., and Noguchi, S.: Lower-Stratospheric Radiative Damping and PolarNight Jet Oscillation Events, J. Atmos. Sci., 70, 1391-1408, https://doi.org/10.1175/JAS-D-12-0193.1, 2013b.
Khosrawi, F., Kirner, O., Sinnhuber, B.-M., Johansson, S., Höpfner, M., Santee, M. L., Froidevaux, L., Ungermann, J., Ruhnke, R., Woiwode, W., Oelhaf, H., and Braesicke, P.: Denitrification, dehydration and ozone loss during the 2015/2016 Arctic winter, Atmos. Chem. Phys., 17, 1289312910, https://doi.org/10.5194/acp-17-12893-2017, 2017.

Kinnersley, J. S. and Tung, K.-K.: Modeling the Global Interannual Variability of Ozone Due to the Equatorial QBO and to Extratropical Planetary Wave Variability, J. Atmos. Sci., 55, 1417-1428, https://doi.org/10.1175/15200469(1998)055<1417:MTGIVO>2.0.CO;2, 1998.

Kodera, K., Kuroda, Y., and Pawson, S.: Stratospheric sudden warmings and slowly propagating zonal-mean zonal wind anomalies, J. Geophys. Res.-Atmos., 105, 12351-12359, https://doi.org/10.1029/2000JD900095, 2000.

Konopka, P., Engel, A., Funke, B., Müller, R., Grooß, J.U., Günther, G., Wetter, T., Stiller, G., von Clarmann, T., Glatthor, N., Oelhaf, H., Wetzel, G., López-Puertas, M., Pirre, M., Huret, N., and Riese, M.: Ozone loss driven by nitrogen oxides and triggered by stratospheric warmings can outweigh the effect of halogens, J. Geophys. Res., 112, D05105, https://doi.org/10.1029/2006JD007064, 2007.

Limpasuvan, V., Thompson, D. W. J., and Hartmann, D. L.: The Life Cycle of the Northern Hemisphere Sudden Stratospheric Warmings, J. Climate, 17, 2584-2596, https://doi.org/10.1175/15200442(2004)017<2584:TLCOTN>2.0.CO;2, 2004.

Livesey, N. J., Santee, M. L., and Manney, G. L.: A Matchbased approach to the estimation of polar stratospheric ozone loss using Aura Microwave Limb Sounder observations, Atmos. Chem. Phys., 15, 9945-9963, https://doi.org/10.5194/acp15-9945-2015, 2015.

London, J.: Ozone variations and their relation to stratospheric warmings, Tech. rep., Meteorol. Abh. der Freien Univ. Berlin, Berlin, Germany, 1963.

Lubis, S. W., Silverman, V., Matthes, K., Harnik, N., Omrani, N.-E., and Wahl, S.: How does downward planetary wave coupling affect polar stratospheric ozone in the Arctic winter stratosphere?, Atmos. Chem. Phys., 17, 2437-2458, https://doi.org/10.5194/acp-17-2437-2017, 2017.

Lubis, S. W., Huang, C. S., and Nakamura, N.: Role of FiniteAmplitude Eddies and Mixing in the Life Cycle of Stratospheric Sudden Warmings, J. Atmos. Sci., 75, 3987-4003, https://doi.org/10.1175/JAS-D-18-0138.1, 2018a.

Lubis, S. W., Huang, C. S. Y., Nakamura, N., Omrani, N.E., and Jucker, M.: Role of Finite-Amplitude Rossby Waves and Nonconservative Processes in Downward Migration of Extratropical Flow Anomalies, J. Atmos. Sci., 75, 1385-1401, https://doi.org/10.1175/JAS-D-17-0376.1, 2018b.

Manney, G. L. and Lawrence, Z. D.: The major stratospheric final warming in 2016: dispersal of vortex air and termination of Arctic chemical ozone loss, Atmos. Chem. Phys., 16, 15371-15396, https://doi.org/10.5194/acp-16-15371-2016, 2016.

Manney, G. L., Froidevaux, L., Santee, M. L., and Livesey, N. J.: Variability of ozone loss during Arctic winter (1991-2000) estimated from UARS Microwave Limb Sounder measurements, J. Geophys. Res., 108, 4149, https://doi.org/10.1029/2002JD002634, 2003.

Manney, G. L., Schwartz, M. J., Krüger, K., Santee, M. L., Pawson, S., Lee, J. N., Daffer, W. H., Fuller, R. A., and Livesey, 
N. J.: Aura Microwave Limb Sounder observations of dynamics and transport during the record-breaking 2009 Arctic stratospheric major warming, Geophys. Res. Lett., 36, L12815, https://doi.org/10.1029/2009GL038586, 2009.

Manney, G. L., Lawrence, Z. D., Santee, M. L., Livesey, N. J., Lambert, A., and Pitts, M. C.: Polar processing in a split vortex: Arctic ozone loss in early winter 2012/2013, Atmos. Chem. Phys., 15, 5381-5403, https://doi.org/10.5194/acp-15-5381-2015, 2015.

Marsh, D. R., Mills, M. J., Kinnison, D. E., Lamarque, J.-F., Calvo, N., and Polvani, L. M.: Climate Change from 1850 to 2005 Simulated in CESM1(WACCM), J. Climate, 26, 7372-7391, https://doi.org/10.1175/JCLI-D-12-00558.1, 2013.

Matsuno, T.: A Dynamical Model of the Stratospheric Sudden Warming, J. Atmos. Sci., 28, 1479-1494, https://doi.org/10.1175/15200469(1971)028<1479:ADMOTS>2.0.CO;2, 1971.

McIntyre, M. E.: How Well do we Understand the Dynamics of Stratospheric Warmings?, J. Meteorol. Soc. Japan. Ser. II, 60, 37-65, 1982.

Morgenstern, O., Hegglin, M. I., Rozanov, E., O’Connor, F. M., Abraham, N. L., Akiyoshi, H., Archibald, A. T., Bekki, S., Butchart, N., Chipperfield, M. P., Deushi, M., Dhomse, S. S., Garcia, R. R., Hardiman, S. C., Horowitz, L. W., Jöckel, P., Josse, B., Kinnison, D., Lin, M., Mancini, E., Manyin, M. E., Marchand, M., Marécal, V., Michou, M., Oman, L. D., Pitari, G., Plummer, D. A., Revell, L. E., Saint-Martin, D., Schofield, R., Stenke, A., Stone, K., Sudo, K., Tanaka, T. Y., Tilmes, S., Yamashita, Y., Yoshida, K., and Zeng, G.: Review of the global models used within phase 1 of the Chemistry-Climate Model Initiative (CCMI), Geosci. Model Dev., 10, 639-671, https://doi.org/10.5194/gmd-10-639-2017, 2017.

Nakamura, N.: Two-Dimensional Mixing, Edge Formation, and Permeability Diagnosed in an Area Coordinate, https://doi.org/10.1175/15200469(1996)053<1524:TDMEFA>2.0.CO;2, 1996.
Newman, P. A., Nash, E. R., and Rosenfield, J. E.: What controls the temperature of the Arctic stratosphere during the spring?, J. Geophys. Res., 106, 19999-20010, https://doi.org/10.1029/2000JD000061, 2001.

Plumb, R. A.: Stratospheric Transport, J. Meteorol. Soc. Japan. Ser. II, 80, 793-809, https://doi.org/10.2151/jmsj.80.793, 2002.

Randel, W. J., Wu, F., and Stolarski, R.: Changes in Column Ozone Correlated with the Stratospheric EP Flux, J. Meteorol. Soc. Japan, 80, 849-862, https://doi.org/10.2151/jmsj.80.849, 2002.

Solomon, S., Kiehl, J. T., Garcia, R. R., Grose, W., Solomon, S., Kiehl, J. T., Garcia, R. R., and Grose, W.: Tracer Transport by the Diabatic Circulation Deduced from Satellite Observations, 43, 1603-1617, https://doi.org/10.1175/15200469(1986)043<1603:TTBTDC>2.0.CO;2, 1986.

Solomon, S., Kinnison, D., Bandoro, J., and Garcia, R.: Simulation of polar ozone depletion: An update, J. Geophys. Res.-Atmos., 120, 7958-7974, https://doi.org/10.1002/2015JD023365, 2015.

Strahan, S. E., Douglass, A. R., and Steenrod, S. D.: Chemical and dynamical impacts of stratospheric sudden warmings on Arctic ozone variability, J. Geophys. Res., 121, 11836-11851, https://doi.org/10.1002/2016JD025128, 2016.

Tao, M., Konopka, P., Ploeger, F., Grooß, J.-U., Müller, R., Volk, C. M., Walker, K. A., and Riese, M.: Impact of the 2009 major sudden stratospheric warming on the composition of the stratosphere, Atmos. Chem. Phys., 15, 8695-8715, https://doi.org/10.5194/acp-15-8695-2015, 2015.

Wegner, T., Kinnison, D. E., Garcia, R. R., and Solomon, S.: Simulation of polar stratospheric clouds in the specified dynamics version of the whole atmosphere community climate model, J. Geophys. Res.-Atmos., 118, 4991-5002, https://doi.org/10.1002/jgrd.50415, 2013.

WMO: Scientific Assessment of Ozone Depletion 2014, Tech. rep., World Meteorological Organization (WMO), Global Ozone Research 5 and Monitoring Project-Report No. 55, Geneva, Switzerland, 2014. 